\title{
Parameterization of sea-salt optical properties and physics of the associated radiative forcing
}

\author{
J. $\mathbf{L i}^{1}$, X. Ma ${ }^{1}$, K. von Salzen ${ }^{1}$, and S. Dobbie ${ }^{2}$ \\ ${ }^{1}$ Canadian Centre For Climate Modelling and Analysis, Science and Technology Branch, Environment Canada, \\ University of Victoria, Victoria, British Columbia, Canada \\ ${ }^{2}$ Institute for Climate and Atmospheric Science, School of Earth and Environment, University of Leeds, Leeds, UK
}

Received: 20 December 2007 - Published in Atmos. Chem. Phys. Discuss.: 19 March 2008

Revised: 27 May 2008 - Accepted: 24 July 2008 - Published: 19 August 2008

\begin{abstract}
The optical properties of sea-salt aerosol have been parameterized at shortwave and longwave wavelengths. The optical properties were parameterized in a simple functional form in terms of the ambient relative humidity based on Mie optical property calculations. The proposed parameterization is tested relative to Mie calculations and is found to be accurate to within a few percent. In the parameterization, the effects of the size distribution on the optical properties are accounted for in terms of effective radius of the sea-salt size distribution. This parameterization differs from previous works by being formulated directly with the wet sea-salt size distribution and, to our knowledge, this is the first published sea-salt parameterization to provide a parameterization for both shortwave and longwave wavelengths.

We have used this parameterization in a set of idealized 1$D$ radiative transfer calculations to investigate the sensitivity of various attributes of sea-salt forcing, including the dependency on sea-salt column loading, effective variance, solar angle, and surface albedo. From these sensitivity tests, it is found that sea-salt forcings for both shortwave and longwave spectra are linearly related to the sea-salt loading for realistic values of loadings. The radiative forcing results illustrate that the shortwave forcing is an order of magnitude greater than the longwave forcing results and opposite in sign, for various loadings. Forcing sensitivity studies show that the influence of effective variance for sea-salt is minor; therefore, only one value of effective variance is used in the parameterization. The dependence of sea-salt forcing with solar zenith angle illustrates an interesting result that sea-salt can generate a positive top-of-the-atmosphere result (i.e. warming) when the solar zenith angle is relatively small (i.e. $<30^{\circ}$ ). Fi-
\end{abstract}

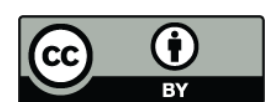

Correspondence to: $\mathrm{J} . \mathrm{Li}$

(jiangnan.li@ec.gc.ca) nally, it is found that the surface albedo significantly affects the shortwave radiative forcing, with the forcing diminishing to zero as the surface albedo tends to unity.

\section{Introduction}

In the last several decades, interest in sea-salt aerosol has increased, partly because it is essential for explaining a significant portion of the differences in clear-sky top-of-theatmosphere irradiance between observations and modeling results over the oceans (Haywood et al., 1997; Li et al., 2006). Globally and annually averaged, sea-salt dominates the radiative transfer in the marine atmosphere compared to all other types of aerosol in terms of the outgoing shortwave irradiance at the top-of-the-atmosphere. Accurate sea-salt radiative properties are not only important for the energy budget of the present-day atmosphere, they are also important for understanding both past and future climate change. As examples, consider that during the Younger Dryas period, sea-salt concentrations were higher than at present by a factor of about three (Alley , 2000). By the end of this century, IPCC scenarios are predicting an increase in sea-salt burden based on future global wind patterns and strengths. This might entail an estimated additional $-0.8 \mathrm{~W} / \mathrm{m}^{2}$ direct seasalt forcing and $-1.16 \mathrm{~W} / \mathrm{m}^{2}$ indirect forcing (Penner et al., 2001). However, considerable uncertainties exist with regard to the magnitude of the sea-salt radiative forcing, especially the indirect forcing. For example, an increase in sea-salt concentrations in the marine boundary layer may lead to either increased or reduced cloud droplet number concentrations, depending on the amount of sulphate aerosol and meteorological situation (e.g., O’Dowd et al., 1999).

Published by Copernicus Publications on behalf of the European Geosciences Union. 

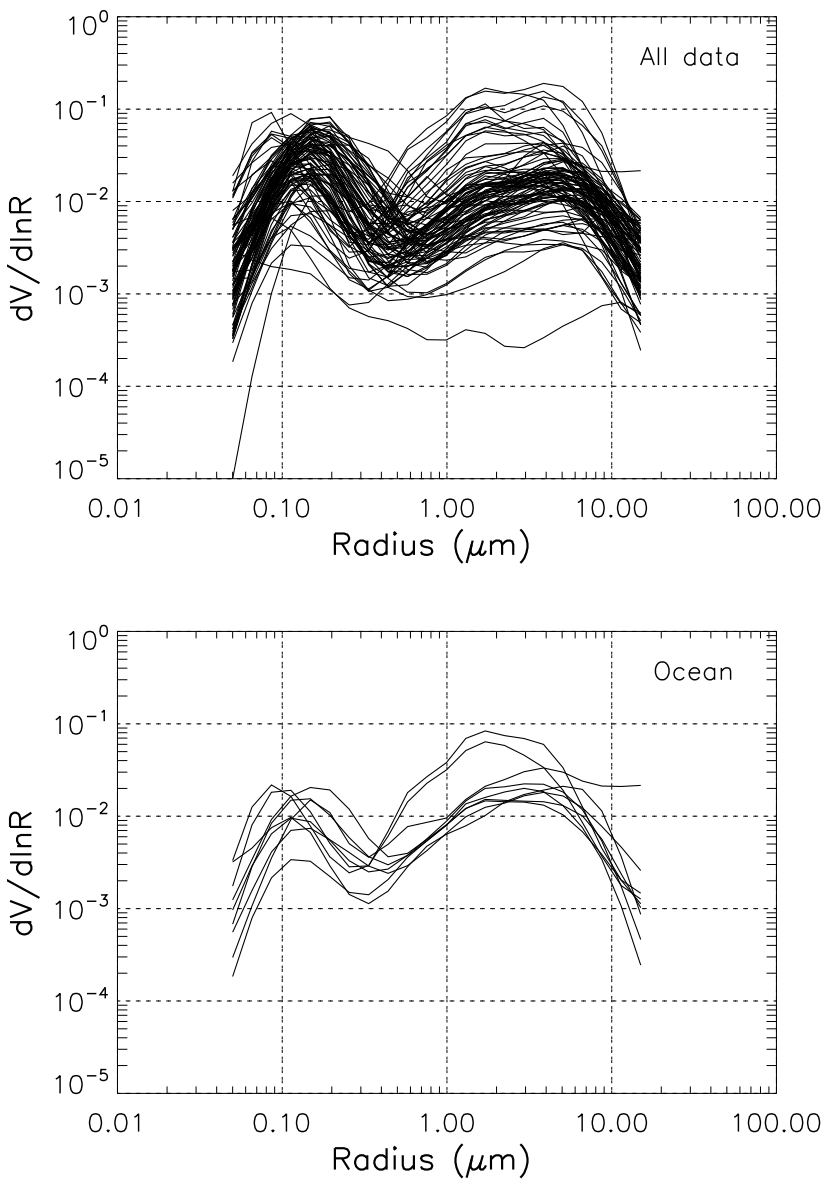

Fig. 1. Upper panel, aerosol size distributions from AERONET for all stations. Lower panel for stations only over ocean with for sites: Bermuda (longitude 295.32, latitude 32.37), Lanai (203.02, 20.82), Azores (331.37, 38.53), Ascension Is. (345.60, -7.97), Barbados (300.50, 13.17), Nauru (166.90, -0.52), Tahiti $(210.40,-17.57)$, Gadeloup (298.50, 16.32), Midway Is. (182.63, 28.20).

The radiative forcing from sea-salt affects a variety of processes such as sensible and latent heat fluxes and consequently the static stability of the atmosphere and its general circulation. Although, shortwave parameterizations of seasalt optical properties exist (Dobbie et al., 2003; Winter and Chýlek, 1997), no parameterization of sea-salt optical properties appear in the literature for the longwave yet, as they do for example for sulphates ( $\mathrm{Li}$ and Min, 2002) and black carbon and organic carbon (Bäumer et al., 2007). Dobbie et al.'s approach is based on a two-mode scheme which separates the sea-salt size distribution into separate particle size categories for accumulation mode and coarse mode sea-salt. Here, a new parameterization for sea-salt longwave and shortwave optical properties is proposed. The approach is based on the assumption of variable sea-salt size distributions and an updated treatment of shortwave optical properties. Sea-salt particles grow (shrink) in size as relative humidity increases (decreases) (Tang et al., 1997) changing not only size but also the water: solute ratio (and hence refractive index). A key aspect of the work has been to provide an accurate representation of the response of sea-salt optical properties and radiative forcings to changes in relative humidity. In many models, aerosol optical properties are either fixed or based on the dry aerosol size distribution for two specified particle size modes with a corresponding growth factor taken at a representative humidity. In contrast, it is proposed here to directly consider the size distribution of the wet sea-salt aerosol particles for optical properties. This method has the advantage over previous methods in that it is more precisely based on the underlying physics related to the sea-salt size distribution.

To understand the physics for the aerosol radiative forcing, we implemented the proposed parameterization scheme in a $1 \mathrm{D}$ column radiative transfer model. We investigated the sensitivity of the simulated forcing to variations in effective radius, effective variance, surface albedo and solar zenith angle. In contrast to other studies based on global climate models, this approach allows a more rigorous evaluation of fundamental aspects of sea-salt radiative forcing.

\section{Sea-salt growth rate and size distribution}

Sea-salt is generated at the ocean surface by various processes, including bubble bursting and the generation of spume droplets. The bursting of bubbles and subsequent ejection of jet droplets into the air represents a major source of sea-salt particles. The jet droplets are solutions of water and sodium chloride and other minor inorganic and organic compounds. In this study, the sea-salt composition is the same as that assumed by (Tang et al., 1997). Further discussions of sea-salt production and properties can be found in Lewis and Schwartz (2004).

After injection, the solution droplets will either grow or evaporate until thermodynamic equilibrium with the atmosphere is reached or fall back to the sea. As the particle size varies with respect to the environmental relative humidity, the concentrations of the solutes in the aerosol particles will vary accordingly, affecting the aerosol mass density, surface tension, refractive indexes, and optical properties.

The wet size distribution of sea-salt aerosol is often approximated by a log-normal distribution (Fitzgerald , 1975), i.e.,

$n(r)=\frac{d N}{d r}=\frac{N_{0}}{\sqrt{2 \pi} r \ln \sigma} \exp \left[-\frac{\left(\ln r-\ln r_{0}\right)^{2}}{2(\ln \sigma)^{2}}\right]$.

In Eq. (1), $r$ is the radius of the aerosol particle, $N_{0}$ is the total number density, $r_{0}$ is the geometric mean radius and $\sigma$ is the geometric standard deviation. The effective radius and effective variance for the log-normal distribution are easily obtained as 
$r_{\mathrm{e}}=\frac{\int_{0}^{\infty} n(r) r^{3} d r}{\int_{0}^{\infty} n(r) r^{2} d r}=r_{0} \exp \left[2.5(\ln \sigma)^{2}\right]$

and

$v_{\mathrm{e}}=\frac{\int_{0}^{\infty}\left(r-r_{\mathrm{e}}\right)^{2} r^{2} n(r) d r}{r_{\mathrm{e}}^{2} \int_{0}^{\infty} r^{2} n(r) d r}=\exp \left[(\ln \sigma)^{2}\right]-1$

In the Canadian Centre for Climate Modelling and Analysis (CCCma) GCM, the sulphate aerosol size distribution has previously been simulated based on a bin method (Ma and von Salzen, 2006) and also based on the more efficient piecewise log-normal approximation (PLA) method (von Salzen, 2006). According to the PLA method, pieces of different lognormal distributions are used within separate sections of the particle size spectrum for a realistic and flexible representation of aerosol size distributions. A smaller number of size sections can be used in simulations with the PLA method compared to the bin method. This results in a numerically more efficient and accurate treatment of aerosol size distributions in atmospheric models.

In Fig. 1, the upper panel shows observed aerosol size distributions according to AERONET (Holben et al., 1998) for a large number of sites around the world. The lower panel only shows the results for ocean sites. An important feature for the observed size distribution in Fig. 1 is the bi-modal shape. The small mode typically corresponds to sulfate aerosol and sea-salt (from the bursting bubble film), and the large mode to sea-salt (from jet and spume sources) and mineral dust. From the available observations it is not straightforward to distinguish between different types of aerosol, including seasalt. In addition, simulated sea-salt distributions from an experimental version of the CCCma AGCM are shown in Ma et al. (2008) for the same locations as the AERONET observations in Fig. 1. It is found that the simulated sea-salt distribution matches reasonably well with the large mode distributions from the AERONET observations, especially for the ocean sites.

Figure 2 shows vertical profiles of the wet aerosol effective radius and effective variance for globally averaged values over oceans based on simulations with CCCma AGCM. The simulated effective radius generally decreases with height owing to aerosol sedimentation and deposition processes. The globally averaged values of the effective radii have a wide range from approximately 1 to $3.5 \mu \mathrm{m}$. The range is even larger for individual grid-points in the simulation. In contrast, the global mean effective variance has a relatively small range of variation in the lower atmosphere.

In previous studies the dry sea-salt can be categorized into two modes, an accumulation mode with $r_{e}=0.732 \mu \mathrm{m}$ and a coarse mode with $r_{e}=6.13 \mu \mathrm{m}$, both with the same $v_{e}=0.65$, based on climatologically representative results (Koepke et al., 1997), in which the mass proportion in the coarse mode is
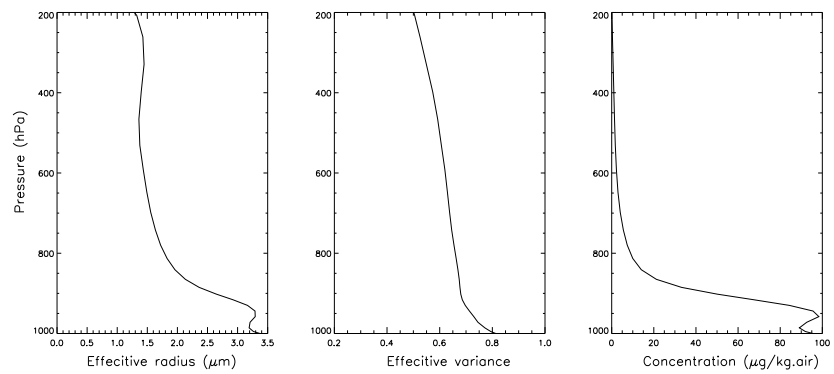

Fig. 2. Vertical profiles of the oceanic global mean effective radius (left panel), effective variance (middle panel) and concentration (right panel) for wet sea-salt particles taken from GCMs calculations.

considered much larger than for the accumulation mode. We note that the AERONET results in Fig. 1 show wet sizes and yet the wet observed sea-salt effective radius is similar to the dry coarse mode effective size for sea-salt assumed above. Assuming the dry size and applying a humidity growth factor, that can be between about 1.5-5 (based on Eq. 5), the set of coarse modes for dry sea-salt will estimate the wet size that is unreasonably large.

For the growth of aerosol particles, the growth factor, $\eta$, is defined as the ratio of the aerosol particle radius $r$ at a specified $\mathcal{H}$ (the relative humidity normalized to unity) to the radius of the corresponding dry aerosol $r_{\mathrm{d}}$,

$\frac{r}{r_{\mathrm{d}}}=\eta\left(r_{\mathrm{d}}, \mathcal{H}\right)$

However, for dry particle size larger than $0.1 \mu \mathrm{m}$ the dependence of the wet growth on dry size becomes very weak except for $\mathcal{H}$ close to $100 \%$. All dry sizes studied show significant growth factors relative to dry, even for moderate $\mathcal{H}$ values, it is just that some variation of the growth dependence with initial dry size is noted for small aerosol sizes and high humidities. Therefore, the growth factor is simplified as $\eta(\mathcal{H})$. According to Lewis and Schwartz $(2004,2006)$, the bulk sea-salt growth factor is represented as

$\eta(\mathcal{H})=\left(\frac{\rho_{d}}{\rho} \frac{1}{x}\right)^{1 / 3}$

where $\rho$ is the solution density for sea-salt particle, $\rho_{d}$ is the density for dry sea-salt, $\rho_{d}=2.24 \mathrm{~g} \mathrm{~cm}^{-3}$ is assumed, $x$ is the solute weight fraction. Following Tang et al. (1997), the solute weight fraction can be obtained from relative humidity through iteration, with the assumption that the relative humidity equals the water activity, since the surface tension contribution is generally negligible for the $\mathcal{H}$ and particle size under consideration (Lewis, 2008). Then the solution density is determined by the solute weight fraction based on Tang et al. (1997). 
It is useful to consider the relationship between dry and wet particle sizes. The number of dry particles in the interval from $r_{\mathrm{d}}$ to $r_{\mathrm{d}}+d r_{\mathrm{d}}$ is required to equal the number of wet particles in the interval from $r$ to $r+d r$. That is, $n_{d}\left(r_{\mathrm{d}}\right) d r_{\mathrm{d}}=n(r) d r$. Consequently, the wet size distribution, $n(r)$, is related to the dry size distribution, $n_{d}\left(r_{\mathrm{d}}\right)$, in the following way

$n_{d}\left(r_{\mathrm{d}}\right) \rightarrow n(r)=n_{d}(r / \eta) \frac{d(r / \eta)}{d r}$.

As the particles grow, the wet size distribution, $n(r)$, shifts toward larger radius sizes. If we assume the dry particle size distribution adheres to the log-normal distribution, then the wet size distribution will be distorted (e.g. stretching) from the log-normal form for the dry particles, and vice versa.

A wet particle size weighted physical quantity $F(r)$ (e.g. extinction) can be calculated directly

$\bar{F}=\int_{0}^{\infty} F(r) n(r) d r / N_{0}$.

Based on Eq. (6), the manner in which the wet size distribution is related to the dry size distribution is specified, and $F(r)$ also can be calculated through the dry size distribution,

$\bar{F}=\int_{0}^{\infty} F\left(\eta r_{\mathrm{d}}\right) n_{d}\left(r_{\mathrm{d}}\right) d r_{\mathrm{d}} / N_{0}$.

The assumption that $\eta$ is only a function of $\mathcal{H}$, according to Eq. (5) in combination with Eq. (6), leads to

$r_{\mathrm{e}}=\frac{\int_{0}^{\infty} n(r) r^{3} d r}{\int_{0}^{\infty} n(r) r^{2} d r} \approx \frac{\eta^{3} \int_{0}^{\infty} n_{d}\left(r_{d}\right) r_{d}^{3} d r_{d}}{\eta^{2} \int_{0}^{\infty} n_{d}\left(r_{d}\right) r_{d}^{2} d r_{d}}=\eta r_{d e}$

where $r_{d e}$ is the effective radius for dry size distribution. It can be easily shown that $v_{e} \approx v_{d e}$, where $v_{d e}$ is the effective variance for the dry aerosol.

Although physical properties can in principle be obtained for wet particle size distributions based on dry particle size distributions according to Eq. (8), this can be problematic for modeling. First, sea-salt particle sizes are considerably different from dry particle sizes at typical atmospheric relative humidities. The conversion from dry to wet sizes therefore needs to be sufficiently well known for accurate results. Further, the assumption of particle effective sizes in radiation calculations should be consistent with assumptions required for simulations of atmospheric transport processes, including sedimentation. Second, a radiation sea-salt optical property parameterization based on a limited number of dry sizes will not adequately represent the physics (growth and associated optical properties) well for much of the potentially diverse range of effective radii that sea-salt can attain between the parameterization effective dry sizes. Using a parameterization based on a few dry effective sizes generally results in inadequate results for optical properties when the effective size is between the parameterization's chosen sizes when used in conjunction with a limited number of interpolation points (see detailed discussion for Figs. 4 and 5). Therefore it appears to a be a natural choice to directly calculate sea-salt optical properties based on wet size distributions in models.

In the early stages of aerosol climate modeling, it was not possible to predict the wet size distribution of sea-salt. At best, different fixed dry modes were considered. For example, the parameterization (Dobbie et al., 2003) was based on $r_{d e}$. Today, more climate models are able to simulate the full wet size distribution, thus parameterizations for sea-salt optical properties should be consistent with the simulated wet sea-salt size distribution.

Based on the above argument, we propose a new approach which directly uses the wet particle distribution. Under the assumption of equilibrium, the growth factor can be calculated through the bulk scheme (Lewis and Schwartz, 2004, 2006) to obtain the droplet density and growth rate based on Tang et al. (1997). This allows the determination of the molar weights of the dry aerosol and water in the wet particles. Accordingly, the refractive index for the wet particles can be determined as the mean of the molar mixing weighted refractive indexes for the dry particle and water (Tang et al., 1997; Wang and Martin, 2006). The refractive index for water and sea-salt are based on Volz (1972); Hale et al. (1973); Shettle and Fenn (1979).

\section{Parameterization of sea-salt optical properties}

The sea-salt optical properties typically required in radiative transfer calculations are the extinction coefficient, single scattering albedo and asymmetry factor for shortwave radiation and specific absorption coefficient for the longwave calculations.

The sea-salt optical depth is

$\tau=\mathrm{WAC} l \psi$,

where $l$ is the geometrical path length, WAC is the wet aerosol content given by

$\mathrm{WAC}=\frac{4 \pi}{3} \int \rho_{a} n(r) r^{3} d r$,

where $\rho_{a}$ is the mass density of the wet aerosols. WAC $l$ is the aerosol loading. In Eq. (7) $\psi$ is the specific extinction

$\psi=\frac{\pi \int Q_{\mathrm{ext}}(\lambda, r) r^{2} n(r) d r}{\mathrm{WAC}}$,

where $Q_{\text {ext }}$ is the extinction efficiency. The single scattering albedo, $\omega$, specifies the fraction of total radiation interacting 
with a particle through scattering and absorption processes. It is defined as

$\omega=\frac{\int Q_{\mathrm{sca}}(\lambda, r) r^{2} n(r) d r}{\int Q_{\mathrm{ext}}(\lambda, r) r^{2} n(r) d r}$,

where $Q_{\text {sca }}$ is the scattering efficiency.

The phase function, $P$, describes the angular distribution of scattered photons for scattering events. The normalized phase function is given by

$P(\theta, \lambda)=\frac{\frac{\lambda^{2}}{2 \pi^{2}} \int\left(i_{1}(\theta, r, \lambda)+i_{2}(\theta, r, \lambda)\right) n(r) d r}{\int Q_{\text {sca }}(\lambda, r) r^{2} n(r) d r}$,

where $\theta$ is the scattering angle and $i_{1}$ and $i_{2}$ are the squares of the vertical and horizontal scattering amplitudes, respectively. The asymmetry factor is $g$, which is the integrated phase function weighted by the cosine of the scattering angle, and equates to one third of the first moment of the Legendre expansion of the phase function.

For the infrared, since the scattering is very weak, the radiative transfer equation can be dramatically simplified $(\mathrm{Li}$, 2002; Bäumer et al., 2007) and only the absorptance depth, $\kappa=$ WAC $1 \xi$, is required, where $\xi$ is the specific absorptance with

$\xi=\psi(1-\omega)$

Equations (11)-(14) are different from the corresponding formulae in Li et al. (2001), Li and Min (2002), and Bäumer et al. (2007), since this work is directly based on the wet particle distribution. The upper bound in integrations for Eqs. (11)-(14) are set as $25 \mu \mathrm{m}$ (Lewis and Schwartz, 2004).

The parameterization is based on five specified values for the effective radii for wet sea-salt size $(0.732 \mu \mathrm{m}, 1.75 \mu \mathrm{m}$, and $2.75 \mu \mathrm{m}, 4.0 \mu \mathrm{m}$, and $6.13 \mu \mathrm{m})$. To obtain the optical properties for other values of effective radius, a Lagrangian interpolation technique can be employed.

It was generally believed that the variation in optical properties for effective variance is smaller than that for the effective radius. The corresponding radiative impact is also small for changes in the effective variance. As shown in Fig. 2, GCM results present a relatively small variation in the effective variance for sea-salt in the atmosphere. According to the simulation results, in the lower troposphere the value of the sea-salt effective variance is generally larger than the commonly used value of 0.65 , which was suggested by the simple two mode dry sea-salt scheme. The sensitivity of the sea-salt radiative forcing to observed variations in the effective variance will be discussed in a later section.

In the development of the parameterization, the humidity was considered to range from $\mathcal{H}=0.45$ to $\mathcal{H}=0.99$. The crystallization point for sea-salt is at about $\mathcal{H}=0.45$. Therefore, for humidity below $\mathcal{H}=0.45$ the sea-salt is considered to be dry. The parameterization for dry sea-salt optical properties
Table 1. Coefficients for the sea-salt parameterization in Eq. (16)(18) for 4 band scheme.

\begin{tabular}{ccccccccc}
\multicolumn{6}{c}{ The band ranges are $0.2-0.69,0.69-1.19,1.19-2.38,2.38-4 \mu \mathrm{m}$ for bands $i=1,2,3,4$} \\
\hline $\begin{array}{c}r_{\mathrm{e}} \\
(\mu \mathrm{m})\end{array}$ & $i$ & $\begin{array}{c}a_{1}^{i} \\
\left(\mathrm{~m}^{2} \mathrm{~g}^{-1}\right)\end{array}$ & $\begin{array}{c}a_{2}^{i} \\
\left(\mathrm{~m}^{2} \mathrm{~g}^{-1}\right)\end{array}$ & $\begin{array}{c}a_{3}^{i} \\
\left(\mathrm{~m}^{2} \mathrm{~g}^{-1}\right)\end{array}$ & $b_{1}^{i}$ & $b_{2}^{i}$ & $c_{1}^{i}$ & $c_{2}^{i}$ \\
\hline 0.732 & 1 & 1.510 & $8.619 \mathrm{e}-1$ & $-1.619 \mathrm{e}-2$ & $1.117 \mathrm{e}-7$ & $4.438 \mathrm{e}-8$ & .7482 & $4.828 \mathrm{e}-2$ \\
& 2 & 1.378 & $6.081 \mathrm{e}-1$ & $-1.190 \mathrm{e}-2$ & $1.140 \mathrm{e}-5$ & $6.103 \mathrm{e}-6$ & .7558 & $4.413 \mathrm{e}-2$ \\
& 3 & .9634 & $3.001 \mathrm{e}-1$ & $-6.526 \mathrm{e}-3$ & $7.928 \mathrm{e}-4$ & $5.915 \mathrm{e}-4$ & .7453 & $3.943 \mathrm{e}-2$ \\
& 4 & .4491 & $1.384 \mathrm{e}-1$ & $-3.318 \mathrm{e}-3$ & $1.964 \mathrm{e}-1$ & $1.202 \mathrm{e}-1$ & .6992 & $9.346 \mathrm{e}-3$ \\
& & & & & & & & \\
1.75 & 1 & .5659 & $3.652 \mathrm{e}-1$ & $-6.879 \mathrm{e}-3$ & $2.769 \mathrm{e}-7$ & $1.347 \mathrm{e}-7$ & .7635 & $3.531 \mathrm{e}-2$ \\
& 2 & .6226 & $3.835 \mathrm{e}-1$ & $-7.186 \mathrm{e}-3$ & $2.704 \mathrm{e}-5$ & $9.128 \mathrm{e}-6$ & .7544 & $4.505 \mathrm{e}-2$ \\
& 3 & .6251 & $3.195 \mathrm{e}-1$ & $-6.057 \mathrm{e}-3$ & $1.397 \mathrm{e}-3$ & $6.123 \mathrm{e}-4$ & .7630 & $4.808 \mathrm{e}-2$ \\
& 4 & .4818 & $1.621 \mathrm{e}-1$ & $-3.428 \mathrm{e}-3$ & $1.466 \mathrm{e}-1$ & $6.311 \mathrm{e}-2$ & .7827 & $3.069 \mathrm{e}-2$ \\
& & & & & & & & \\
& 1 & .3410 & $2.177 \mathrm{e}-1$ & $-4.115 \mathrm{e}-3$ & $4.179 \mathrm{e}-7$ & $2.752 \mathrm{e}-7$ & .7854 & $2.749 \mathrm{e}-2$ \\
& 2 & .3689 & $2.382 \mathrm{e}-1$ & $-4.491 \mathrm{e}-3$ & $4.565 \mathrm{e}-5$ & $1.441 \mathrm{e}-5$ & .7622 & $3.707 \mathrm{e}-2$ \\
& 3 & .3984 & $2.382 \mathrm{e}-1$ & $-4.454 \mathrm{e}-3$ & $2.218 \mathrm{e}-3$ & $7.855 \mathrm{e}-4$ & .7616 & $4.748 \mathrm{e}-2$ \\
& 4 & .3797 & $1.584 \mathrm{e}-1$ & $-3.048 \mathrm{e}-3$ & $1.497 \mathrm{e}-1$ & $4.436 \mathrm{e}-2$ & .8000 & $3.921 \mathrm{e}-2$ \\
& & & & & & & & \\
4 & 1 & .2291 & $1.447 \mathrm{e}-1$ & $-2.735 \mathrm{e}-3$ & $5.689 \mathrm{e}-7$ & $4.658 \mathrm{e}-7$ & .8036 & $2.442 \mathrm{e}-2$ \\
& 2 & .2420 & $1.556 \mathrm{e}-1$ & $-2.948 \mathrm{e}-3$ & $6.834 \mathrm{e}-5$ & $2.253 \mathrm{e}-5$ & .7783 & $2.926 \mathrm{e}-2$ \\
& 3 & .2619 & $1.669 \mathrm{e}-1$ & $-3.129 \mathrm{e}-3$ & $3.323 \mathrm{e}-3$ & $1.091 \mathrm{e}-3$ & .7653 & $4.247 \mathrm{e}-2$ \\
& 4 & .2772 & $1.385 \mathrm{e}-1$ & $-2.550 \mathrm{e}-3$ & $1.643 \mathrm{e}-1$ & $3.287 \mathrm{e}-2$ & .8072 & $4.410 \mathrm{e}-2$ \\
& & & & & & & & \\
6.13 & 1 & .1506 & $9.445 \mathrm{e}-2$ & $-1.786 \mathrm{e}-3$ & $8.133 \mathrm{e}-7$ & $7.309 \mathrm{e}-7$ & .8195 & $2.357 \mathrm{e}-2$ \\
& 2 & .1562 & $9.888 \mathrm{e}-2$ & $-1.876 \mathrm{e}-3$ & $1.019 \mathrm{e}-4$ & $3.670 \mathrm{e}-5$ & .8000 & $2.391 \mathrm{e}-2$ \\
& 3 & .1653 & $1.067 \mathrm{e}-1$ & $-2.013 \mathrm{e}-3$ & $5.079 \mathrm{e}-3$ & $1.707 \mathrm{e}-3$ & .7795 & $3.384 \mathrm{e}-2$ \\
& 4 & .1810 & $1.055 \mathrm{e}-1$ & $-1.929 \mathrm{e}-3$ & $1.914 \mathrm{e}-1$ & $2.375 \mathrm{e}-2$ & .8147 & $4.527 \mathrm{e}-2$ \\
& & & & & & & &
\end{tabular}

is also provided based on the same effective radii and effective variances as for the wet case.

For the optical properties in the shortwave range, the wavelengths from 0.2 to $4 \mu \mathrm{m}$ are considered, with 25 single wavelength results. In the infrared, wavelengths from 4 to $1000 \mu \mathrm{m}$ are considered, with 39 single wavelength results. Aerosol optical properties as functions of wavelength are much smoother than gaseous optical properties. Therefore, even in a correlated $k$-distribution model, the aerosol optical properties are treated based on the band averaged results. For shortwave radiation, the band average is obtained through a weighting of the results for each single wavelengths by the incoming shortwave spectrum at the top of the atmosphere. A weighting at the top of the sea-salt layer could also be considered but variations in sea-salt layer height and variations in the gaseous concentrations make this a considerable task with minimal benefit.

The band averaged specific extinction coefficient, single scattering albedo and asymmetry parameter for each band, $i$, are parameterized in the following way:

$$
\begin{aligned}
\psi_{i} & =a_{1}^{i}+a_{2}^{i} \mathcal{H}+\frac{a_{3}^{i}}{(\mathcal{H}-1.05)} \\
1-\omega_{i} & =b_{1}^{i}+b_{2}^{i} \mathcal{H} \\
g_{i} & =c_{1}^{i}+c_{2}^{i} \mathcal{H},
\end{aligned}
$$

The form of the parameterizations are chosen because of their simple form. The parameterization coefficients $a_{n}^{i}, b_{n}^{i}$, and $c_{n}^{i}$ are obtained by least squares fitting to the exact Mie calculation results. For each value of a reference effective 


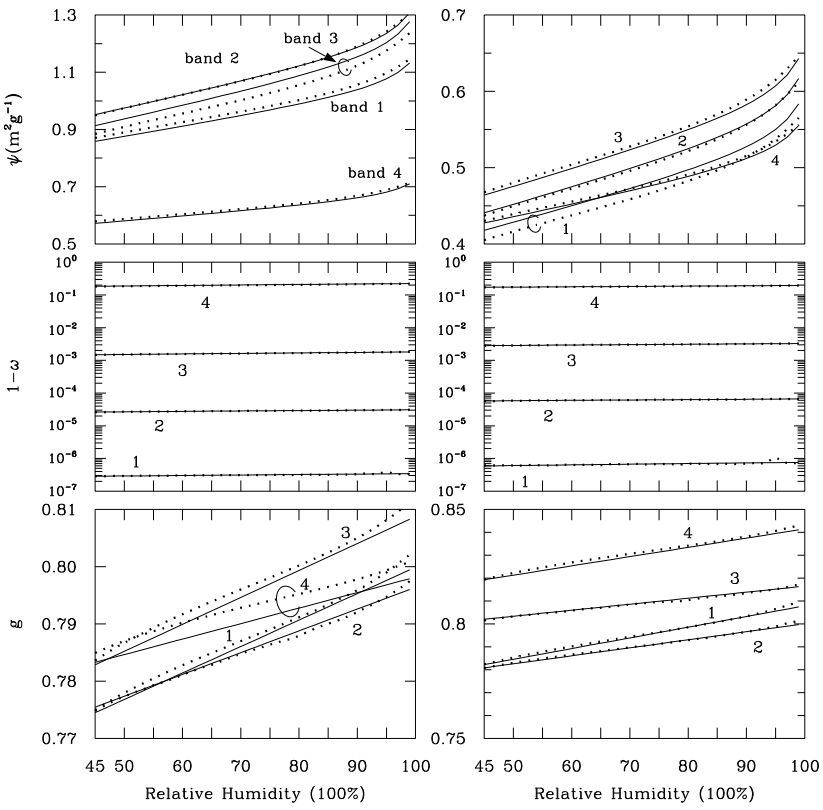

Fig. 3. The variation of the optical properties of specific extinction coefficient, single scattering co-albedo and asymmetry parameter as functions of relative humidity for sea-salt. Two effective radii are considered as $r_{\mathrm{e}}=1.5 \mu \mathrm{m}$ (left column) and $r_{\mathrm{e}}=3 \mu \mathrm{m}$ (right column), both for an effective variance $v_{\mathrm{e}}=0.65$. The theoretical calculations are shown as solid lines and the results by the proposed parameterization with a 5-point Lagrangian interpolation are indicated by dotted lines. Note, any bias is due to the interpolation scheme and not due to the fitting at parameterization effective sizes. Circles identify dotted and solid lines for the same band.

radius and each effective variance, a group of values for $\psi_{i}$, $\omega_{i}$ and $g_{i}$ is provided. Results for $a_{n}^{i}, b_{n}^{i}$, and $c_{n}^{i}$ are shown in Table 1 for a 4 band scheme. The variation of $1-\omega_{i}$ and $g$ are relatively smaller compared to $\psi_{i}$, therefore linear fitting can produce accurate results with relative error less than $1 \%$.

Similar to the treatment for shortwave radiation, a band averaged weighted mean is applied to the longwave parameterization. The average value of specific absorptance for band $i$ is defined as,

$\xi_{i}=\int_{\Delta \lambda_{i}} \xi_{\lambda} B_{\lambda}(T) d \lambda / \int_{\Delta \lambda_{i}} B_{\lambda}(T) d \lambda$.

where $B_{\lambda}(T)$ is the Planck function at wavelength $\lambda, T$ is the temperature and $\Delta \lambda_{i}$ is the spectral interval for band $i$. Eq. (19) is physically similar to the Chandraskhar mean. $T=273 \mathrm{~K}$ is used in the weighting process since sea-salt is mostly located in the lower atmosphere. Similarly, $\xi_{i}$ is parametrized as

$\xi_{i}=d_{1}^{i}+d_{2}^{i} \mathcal{H}+\frac{d_{3}^{i}}{(\mathcal{H}-1.05)}$.
In contrast to the shortwave case, in which the spectral range of the 4 band scheme is a popular choice (Dobbie et al., 1999), there is significant variations in the band structures of different radiation algorithms for the longwave. Therefore, we do not provide any band averaged coefficients for the longwave (to obtain coefficients for individual band averaging, contact the corresponding author).

For shortwave wavelengths, it is found that the specific extinction shows a completely different behavior in response to changes in $\mathcal{H}$ for different values of the effective radius. However for the longwave, the behavior of specific absorptance in response to changes in $\mathcal{H}$ is very similar for different values of the effective radius. In the shortwave wavelength range, the ratio of the wavelength to particle size is small; while for the infrared the ratio is very large. From Mie theory the absorption is more sensitive to this ratio only when the ratio is small. We parameterize the longwave optical property based on the same five values of $r_{e}$ in order to achieve the accurate result and consistency with the treatment for shortwave radiation.

It is found that the parameterized optical properties as functions of relative humidity match very well the results from exact Mie calculations for the five selected values of the effective radius $r_{e}$. The sea-salt optical properties for other values can be obtained through Lagrangian interpolation between the five values of $r_{e}$ (Table 1). As an illustration, Figure 3 shows interpolated results for sea-salt at $r_{e}=1.5 \mu \mathrm{m}$ and $r_{e}=3 \mu \mathrm{m}$, both with $v_{e}=0.65$. It is found that the interpolated results generally agree very well with Mie calculations. The relative error of specific extinction coefficient is within $2 \%$. The relative error for the asymmetry factor in band 4 at $r_{e}=1.5 \mu \mathrm{m}$ is within $0.4 \%$. Overall, the results in Fig. 3 illustrate that the simple parameterization developed here is able to provide accurate values for the optical properties at arbitrary values of $r_{e}$.

In Fig. 3, it is interesting to note that the specific extinction coefficient is largest for band 3. For aerosol with small size, usually the specific extinction is larger for smaller shortwave wavelength, thus the largest specific extinction would be expected to occur for band 1 . We find this is true for the case with $r_{e}=0.732$; however for larger particle sizes, the back scattering becomes weaker and absorption becomes stronger. These two effects reduce the extinction at short wavelengths (where scattering is important) and enhance the extinction in the longer wavelengths (where absorption is important).

As mentioned above, in principle the aerosol optical properties can also be calculated based on dry size distributions according to Eq. (8). We can use the approximate relationship $r_{e} \approx \eta r_{d e}$ with $\eta$ given by the parameterization shown in Lewis and Schwartz (2006) to determine optical properties in terms of $r_{d e}$. Also, for a given $r_{d e}$, the Lagrangian interpolation can be used to create the sea-salt optical properties based on the pre-calculated results for a number of $r_{d e}$. On the other hand, the two mode dry scheme Dobbie et al. (2003) 
cannot be expected to work in this case, since an interpolation based on only two points is not sufficiently accurate.

Here we used an 8-point Lagrangian interpolation method based on $r_{d e}=0.35,0.5,0.732,1.2,1.75,2.75,4$ and $6.13 \mu \mathrm{m}$. Note that this includes the values $r_{d e}=0.732$ and $6.13 \mu \mathrm{m}$ which allows direct comparisons with results from the two mode dry scheme. Although more Lagrangian interpolation points are used than for the wet approach shown in Fig. 3, the results for the dry approach shown in Fig. 4 are overall poor compared to Fig. 3. In Fig. 4, the errors are relatively small for the single scattering albedo and asymmetry factor, but errors are large for the specific extinction coefficient, especially for large values of $\mathcal{H}$. Even the 8-point Lagrangian interpolation cannot produce sufficiently accurate results under these conditions. In order to obtain accurate results, a much higher number of interpolation points would be required. However, from the direct wet method, a few interpolation points can produce very accurate results.

These results give evidence that simulations of sea-salt optical properties in climate models should be directly based on the wet size distribution. While it is possible to determine optical properties for dry particles based on wet particles, the opposite is less straightforward.

\section{Physics of sea-salt radiative forcing}

In order to quantify the radiative impact of sea-salt, we use a one-dimensional radiative transfer model. A onedimensional radiative transfer model has the advantage over a General Circulation Model that it is much easier to analyze fundamental factors that determine the sea-salt direct forcing. More general results for sea-salt direct forcings in the global atmosphere were previously published by Ma et al. (2008).

The radiation algorithm of the Canadian Centre for Climate Modelling and Analysis is used here. This radiation model is a correlated $k$-distribution scheme for gaseous transmission ( $\mathrm{Li}$ and Barker, 2005). For shortwave radiation, water vapor, $\mathrm{CO}_{2}, \mathrm{O}_{3}, \mathrm{CH}_{4}$ and $\mathrm{O}_{2}$ are considered for gaseous transmission. For longwave radiation, water vapor, $\mathrm{CO}_{2}$, $\mathrm{O}_{3}, \mathrm{CH}_{4}, \mathrm{O}_{3}, \mathrm{CH}_{4}, \mathrm{~N}_{2} \mathrm{O}, \mathrm{CFC}_{11}$, and $\mathrm{CFC}_{12}$ are considered for gaseous transmission. For cloud and aerosol optical properties, there are 4 bands covering $0.2-4 \mu \mathrm{m}$ and 9 bands covering from 4-1000 $\mu \mathrm{m}$. We will present forcing calculations for standard atmospheric profiles for mid-latitude summer (MLS) and sub-Arctic winter (SAW) from McClatchey (1972). Selected shortwave and longwave radiative forcing results evaluated at the tropopause $(200 \mathrm{mb})$ and surface will be presented. The sensitivity of forcing to the total loading, the surface albedo, the solar zenith angle and dependence of effective variance will be investigated.

First, the radiative forcing is calculated using the sea-salt effective radius, effective variance and concentration profiles shown in Fig. 2. The vertically integrated loading shown in Fig. 2 is $0.136 \mathrm{gm}^{-2}$. By converting the wet concentra-
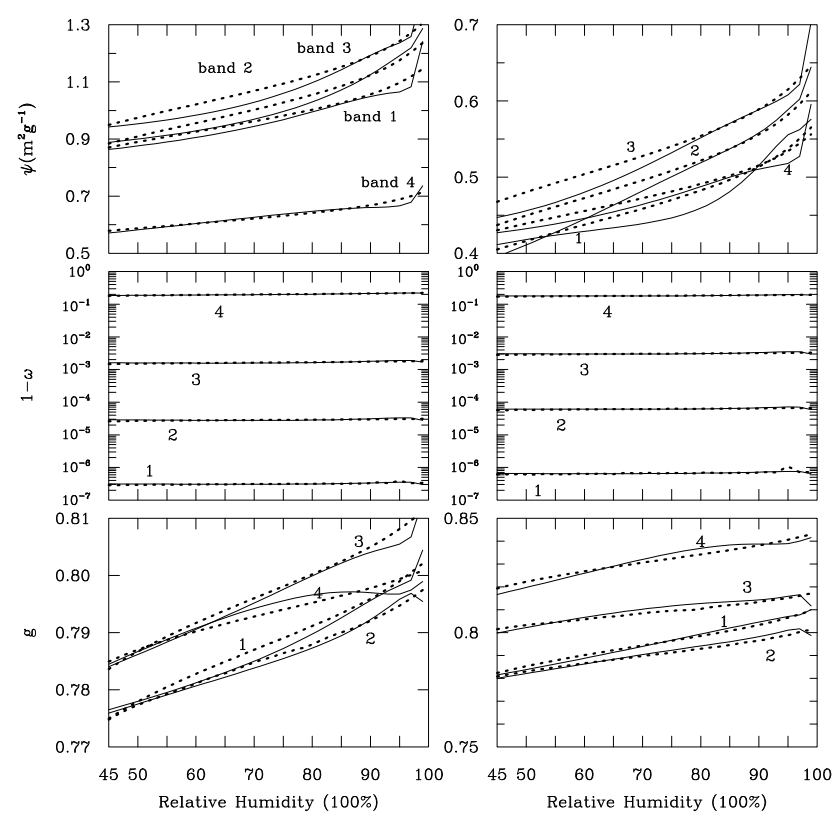

Fig. 4. The same as Fig. 3 but parameterization is based on a dry aerosol size distribution with an 8-point Lagrangian interpolation.

tion to dry concentration using equilibrium theory, we obtain a global oceanic mean dry sea-salt loading of $0.0133 \mathrm{gm}^{-2}$. This value is in good agreement with corresponding results from other models that were used in the AEROCOM project (Schulz et al., 2006). Note, that the concentration in Fig. 2 is the oceanic global mean, which is supposed to be higher than the global mean result since the sea-salt concentration is much lower over land.

In order to study the response of the forcing to the seasalt loading, the sea-salt loading is varied from 0 to $2.0 \mathrm{gm}^{-2}$ by scaling the concentration profile in Fig. 2 . The observed maximum sea-salt loading is generally less than $0.2 \mathrm{gm}^{-2}$ (Holben et al., 1998). Results are shown in Fig. 5. The forcing is defined as the difference in the net radiative flux at $200 \mathrm{mb}$ from two simulations, one with and the other without the aerosol. Also the forcing at surface is shown. In Fig. 5, the solar zenith angle is set to be $53^{\circ}$ which represents the daily average value for the global mean. The surface albedo is set to 0.1 .

It is shown in Fig. 5 that for an oceanic global mean loading of $0.136 \mathrm{gm}^{-2}$, the sea-salt shortwave radiative forcing at $200 \mathrm{mb}$ and surface is about $10 \mathrm{Wm}^{-2}$. The longwave forcing is about $1 \mathrm{Wm}^{-2}$ at the surface and negligible at $200 \mathrm{mb}$. It is interesting to note that the response in forcing is almost linearly related to the loading, even for the high loading value of $0.5 \mathrm{gm}^{-2}$.

Generally, the sea-salt optical depth in the simulations is very small, thus the radiative effect of sea-salt could in principle be treated as a perturbation. For sufficiently small perturbations, the response to a perturbed quantity is usually 

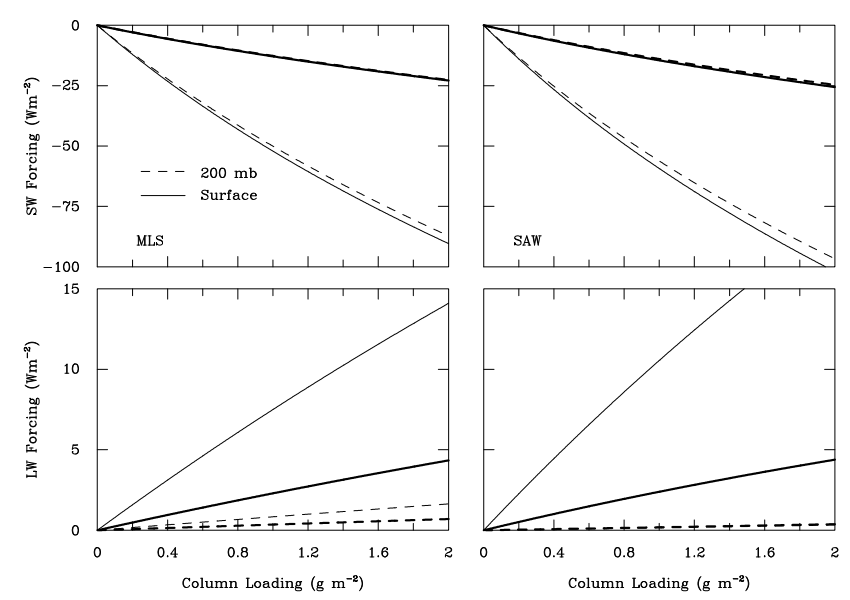

Fig. 5. The sea-salt shortwave radiative forcing (upper panels) and longwave radiative forcing (lower panels) at $200 \mathrm{mb}$ (dashed lines) and at surface (solid lines). Two atmospheric profiles of MLS (middle latitude summer) and SAW (sub-Arctic winter) are considered. The sea-salt vertical profiles of $r_{e}, v_{e}$ and concentration are the same as for Fig. 2. Concentrations are scaled linearly relative to the profiles shown in Fig. 2 (as discussed in the text). The corresponding thick lines refer to results for the same input conditions but with a low cloud located between 751 to $822 \mathrm{mb}$ with a liquid water content of $0.28 \mathrm{gm}^{-3}$.

linear, even for a non-linear problem (see the later discussion of Eq. 21). The simulated forcings are different for MLS and SAW despite identical aerosol properties in the calculations. The SAW atmosphere is drier. This produces less attenuation (i.e. sum of scattering and absorption) of shortwave radiance by water vapor above the layer with high sea-salt concentrations in the lower atmosphere. The relatively large incident shortwave flux produces a larger sea-salt forcing compared to MLS case. The sea-salt shortwave forcing is slightly lower at $200 \mathrm{mb}$ in comparison with the forcing at the surface, for a given loading. At $200 \mathrm{mb}$, the shortwave forcing is mainly caused by the change of upward flux due to scattering by the sea-salt, while at the surface the shortwave forcing is mainly caused by the attenuation of the downward flux.

For the longwave, the radiative forcing is about one order of magnitude smaller than the corresponding shortwave forcing and is opposite in sign. The negative shortwave forcing means that the sea-salt acts to reduce the shortwave energy reaching the lower troposphere and thus causes a cooling, whereas the positive longwave forcing means that the sea-salt acts like a greenhouse gas in that it acts to prevent radiation loss to space. In a similar fashion to the shortwave forcing in which the change is mainly caused by the change in the upward flux, the longwave forcing at surface is caused by the change in the downward flux. Aerosols can reduce the downward flux of the longwave radiation and also can enhance the emission to the surface. The aerosol longwave direct forcing for the downward flux is determined by these two opposing factors.
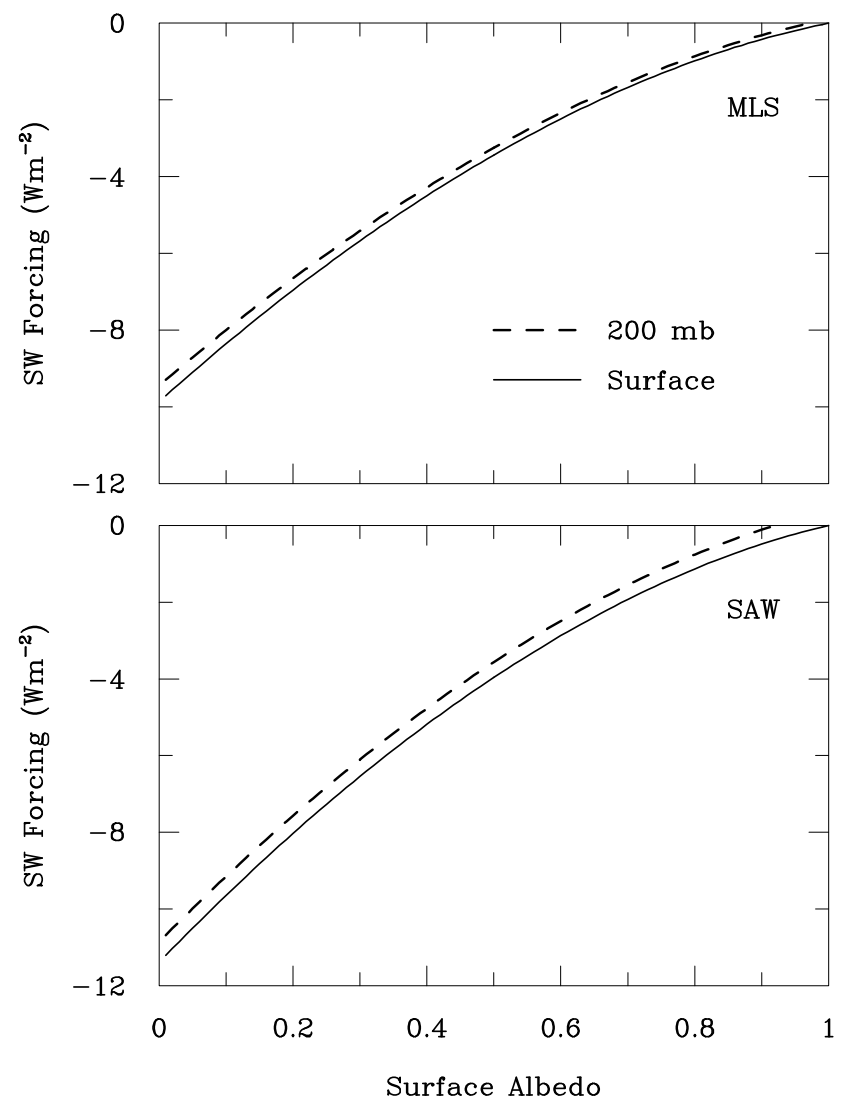

Fig. 6. The sea-salt shortwave radiative forcing versus surface albedo. The atmospheric profile and sea-salt vertical profiles are the same as in Fig. 2. The solar zenith angle is $53^{\circ}$.

The sea-salt longwave forcing is extremely small at $200 \mathrm{mb}$, generally less than $0.1 \mathrm{Wm}^{-2}$. In order to explain the weak infrared forcing at the tropopause, a simple analytical approach has been developed. We first assume that the sea-salt is located in the lower atmosphere. For simplicity, we assume an isothermal longwave radiation source, i.e. a constant Planck function, $B$, for the temperature at the middle of the aerosol layer. The solution for the upward flux for longwave radiative transfer through such aerosol layers is given by (Li, 2002),

$F^{\uparrow}=F_{0}^{\uparrow} e^{-\kappa / \mu_{1}}+\left(1-e^{-\kappa / \mu_{1}}\right) B$,

where $\kappa$ is the total absorptance depth with no aerosol contribution, $F^{\uparrow}$ is the upward out-going flux from the considered layer and $F_{0}^{\uparrow}$ is the incoming flux from the surface, $1 / \mu_{1}$ is the diffusivity factor. Assuming the aerosol layer with absorptance depth $\Delta \kappa(\Delta \kappa<<\kappa)$, the forcing is

$$
\begin{aligned}
& \Delta F^{\uparrow}=-F_{0}^{\uparrow} e^{-(\kappa+\Delta \kappa) / \mu_{1}}-\left(1-e^{-(\kappa+\Delta \kappa) / \mu_{1}}\right) B \\
& +F_{0}^{\uparrow} e^{-\kappa / \mu_{1}}+\left(1-e^{-\kappa / \mu_{1}}\right) B \approx\left(F_{0}^{\uparrow}-B\right) e^{-\kappa / \mu_{1}} \Delta \kappa .
\end{aligned}
$$


In the lower atmosphere, the difference in temperature between the atmosphere and surface is small. Therefore the values of $F_{0}^{\uparrow}$ and $B$ are similar and the forcing is small. Generally $F_{0}^{\uparrow}>B$, thus the longwave forcing at the tropopause is positive, but the sign of the forcing may change if there is a strong temperature inversion in the lower atmosphere.

Equation (22) can be used to interpret the linear response of shortwave and longwave forcing to the loading as shown in Fig. 5. In the shortwave case, the forcing calculation is less straightforward compared to the longwave owing to scattering of shortwave radiation. However, a linearized treatment is appropriate for both forcings owing to relatively small perturbations (see previous discussion).

The thick lines in Fig. 5 show the sea-salt forcing under the same condition but with a low cloud appearing between 751 to $822 \mathrm{mb}$ (the cloud liquid content is specified as $0.28 \mathrm{gm}^{-3}$ ). The introduction of a cloud acts to reduced the sea-salt forcing for both cases because the back scattering of shortwave radiation is dominated by the cloud.

Similarly, the response of the shortwave forcing to variations in surface albedo is shown in Fig. 6. The aerosol concentration is given in Fig. 2 and the solar zenith angle is the same as for Fig. 5. The ocean is optically dark with an albedo that is generally less than 0.1 . We note that seasalt over highly reflective surfaces such as sea-ice can have a dramatic impact on the forcing, leading to large reduction in the magnitude of the forcing as the albedo of the surface approaches unity. This is easy to understand for the shortwave forcing at the surface since the magnitude of the net shortwave flux at the surface diminishes as the surface albedo approaches unity. For the forcing at $200 \mathrm{mb}$, the reduction of the magnitude of the forcing is mostly caused by a reduction in the difference in the reflected upward fluxes (with and without aerosol input). Over a high albedo, more photons are reflected back to the space, and so the effect of reflection by the aerosol layer does not make a significant difference to the total reflection, so the effect on the forcing is minimal. The sea-salt shortwave forcing also varies with the solar zenith angle. For Fig. 7, the sea-salt input is the same as for Fig. 6 but with a solar zenith angle varying from 0 to $90^{\circ}$ and for a surface albedo of 0.1. It is found for both the MLS and SAW that the shortwave forcing is positive for zenith angles less than about $30^{\circ}$. For larger solar zenith angles, the shortwave forcing becomes negative. Therefore the commonly accepted concept of negative sea-salt shortwave forcing does not apply under these circumstances. The sign of sea-salt forcing is highly dependent on the direction of incoming shortwave radiation. When the solar zenith angle is small, the scattering by the sea-salt is mostly downwards. Effects of sea-salt on downward scattering are relatively small so that the fluxes do not depend strongly on the amount of sea-salt. However, the shortwave flux reflected by the surface and escaping to space is reduced by the absorption in the sea-salt layer at near infrared bands. For larger solar zenith angles, the up-scatter

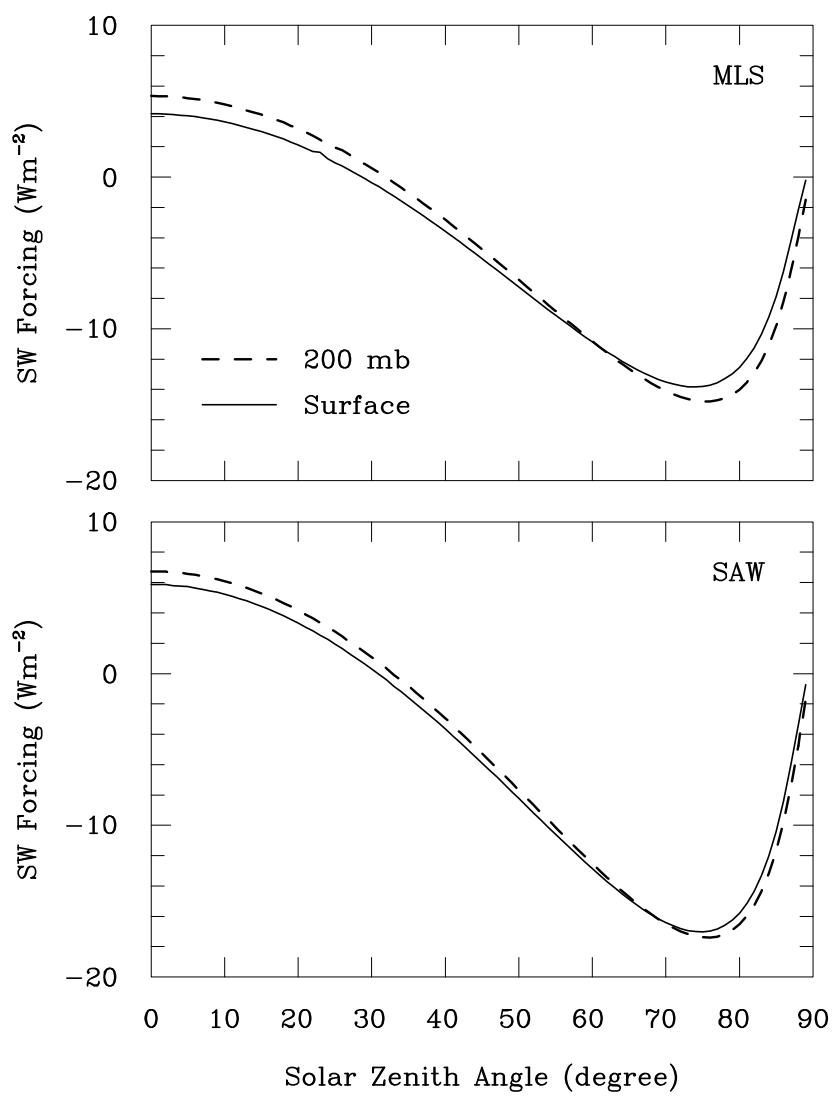

Fig. 7. The sea-salt shortwave radiative forcing versus solar zenith angle. The atmospheric profile and sea-salt vertical profiles are the same as for Fig. 2. A surface albedo of 0.1 is assumed.

from the sea-salt increases as the incident angle increases. In this case, the strong forward scattering in the phase function begins to contribute to the up-scatter and hence reflection.

The negative shortwave forcing does not increase monotonically with solar zenith angle, and for very large angles the magnitude of the forcing becomes very small. Two competing factors are important. As the solar zenith angle gets larger, the incoming radiation is more horizontal in direction. This is associated with an increased probability that the strong forward diffraction peak will contribute to the upscatter and reflection. On the contrary, the increased solar zenith angle decreases the flux to the sea-salt layer. In the limit of grazing incident radiation, the flux and consequently forcing tends to zero. The result of the competition of these two processes is a maximum negative forcing at about $75^{\circ}$.

It is worthy to point out the positive solar forcing found here does not occur for sulfate aerosols. For sulfate aerosol, our calculations show that the radiative forcing for sulfate aerosol is always negative even at $0^{\circ}$ solar zenith angle. The particle size of sulfate aerosol is about one order smaller than that of sea-salt. The forward scattering therefore is weak and above physical explanation of positive forcing does not apply. 


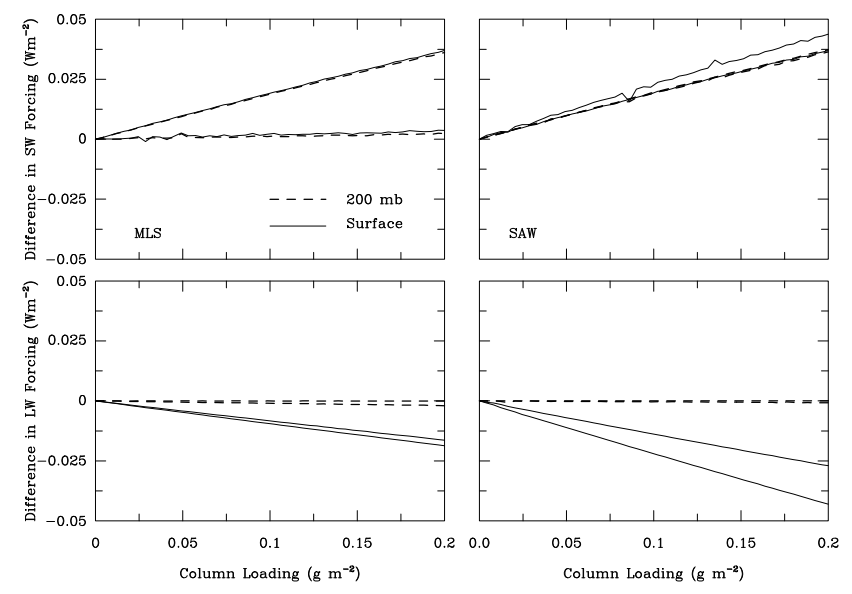

Fig. 8. The differences in radiative forcing between constant $v_{e}$ against the results of Fig. 5 (clear sky case) with $v_{e}$ profile shown in Fig. 2. All other input parameters are the same as those for Fig. 5 (clear sky case). $\Delta v_{e} 1=v_{e}(0.4)-v_{e}$ (Fig.2) represents the results for constant $v_{e}=0.4$ relative to the results for $v_{e}$ from the profile shown in Fig. 2. $\Delta v_{e} 2=v_{e}(0.8)-v_{e}$ (Fig.2) represents the results for constant $v_{e}=0.8$ relative to the results for $v_{e}$ from the profile shown in Fig. 2. Circles identify dotted and solid lines for the same effective variance.

The positive shortwave forcing for small solar zenith angle may partly explain small negative sea-salt shortwave forcing observed in the tropics, since small solar zenith angles occur more frequently in the tropics compared to the extratropics. Of course, another very important reason for small shortwave sea-salt forcings in the tropics is the relatively low wind speed compared to the extratropics which are generally associated with lower production rates for sea-salt particles.

The aerosol effective radius plays a critical role in radiative transfer. This is particularly true for the shortwave spectrum. For a given aerosol burden, smaller particles reflect more shortwave energy to space relative to large particles. This is because smaller particles have a much smaller forward scattering peak. However, the differences in forcing for changes in effective variance are not believed to be important for radiative forcing (Chýlek and Wong, 1995). To our knowledge, this has not been verified with calculations using observed values of $v_{e}$ in the real atmosphere. In order to investigate the impact of $v_{e}$ on forcings, we used the same seasalt input as for Fig. 5, but replaced the $v_{e}$ profile shown in Fig. 2 with two constant values $v_{e}=0.4$ and 0.8 , respectively. The differences in forcings for $v_{e}=0.4\left(v_{e}=0.8\right)$ relative to the results for Fig. 5 with a vertically varying $v_{e}$ taken from Fig. 2 are shown in Fig. 8. According to Fig. 8, results are not sensitive to $v_{e}$ for both shortwave and longwave. The maximum difference is less than $0.2 \mathrm{Wm}^{-2}$. Compared to the results in Fig. 5, the relative difference in the forcings is very small. As $v_{e}$ increases, compensating effects of greater numbers of larger and smaller particles as well as a reduc- tion in the mid-range lead to this effect. We therefore use $v_{e}=0.65$, as presented in Table 1 .

\section{Conclusions}

We have presented a new parameterization of the shortwave and longwave optical properties for sea-salt aerosol. The shortwave part of the parameterization represents an improvement over previous work (Dobbie et al., 2003) by using an efficient method for the calculation of the optical properties based on the wet sea-salt aerosol size distribution. For the longwave, we note this to be the first parameterization for sea-salt optical properties to appear in the literature. The parameterization is based on results from Mie calculations for five values of the effective radius. A Lagrangian interpolation is proposed to obtain results for other values of the effective radius. Results for sea-salt aerosol optical properties are in better agreement with Mie calculations for a wide range of aerosol particle sizes compared to a two mode scheme based on dry sea-salt aerosol size distribution.

It is shown that the effective variance has only a small impact on sea-salt radiative forcings, based on values of the effective variance varying from 0.5 to 0.8 for the studied atmospheric profiles. We have therefore used a single value for this parameterization of $v_{e}=0.65$.

Variations in sea-salt size distributions in terms of effective radius and sea-salt column loading have been shown to have a strong impact on radiative forcings. Both the sea-salt shortwave forcing and longwave forcing were shown to respond nearly linearly to the sea-salt loading for a realistic range of values. The nearly linear response can be attributed to the relatively small perturbation of sea-salt aerosol to the radiative transfer process in the atmosphere. It is further confirmed that the surface albedo can substantially affect the sea-salt shortwave forcing, with the forcing diminishing toward zero as the surface albedo tends to unity.

It is interesting to note that sea-salt can generate a positive shortwave forcing when the solar zenith angle is less than $30^{\circ}$. For small solar zenith angles, the scattering in the seasalt layer is mostly forward and downward with only small effects of sea-salt on back scattering of the shortwave radiation. The absorbing components of sea-salt, however, cause a reduction in the shortwave flux reaching the surface and therefore may lead to a positive shortwave forcing. These results should be emphasized since traditionally it is assumed that the sea-salt shortwave forcing is negative. Also, it is interesting to note that the sea-salt longwave forcing can be negative when there is a large temperature inversion in the lower atmosphere. We note that in general the shortwave forcing is greater than the longwave forcing by an order of magnitude for the results presented.

This work offers a versatile and efficient parameterization for sea-salt at shortwave and longwave wavelengths that is appropriate for implementation in GCMs. We note that 
the parameterization presented in the paper can be modified for other band structures. Parameterization coefficients in Eqs. (16-18) for the 25 single wavelength values between 0.2 to $4 \mu \mathrm{m}$ and the coefficients in Eq. (20) for 39 single wavelength values between 4 to $50 \mu \mathrm{m}$ are available from the authors. Also the data of sea-salt optical properties for radii less than $0.732 \mu \mathrm{m}$ and larger than $6.13 \mu \mathrm{m}$ are available upon request.

Acknowledgements. We are grateful to R. Lewis and C. Reader and three anonymous reviewers for their constructive comments.

Edited by: V. Fomichev

\section{References}

Alley, R. B.: The Younger Dryas cold interval as viewed from central Greenland, Quaternary Sci. Rev., 19 213-226, 2000.

Bäumer, D., Lohmann, U., Lesins, G., Li, J., and Croft, B.: Parameterizing the optical properties of carbonaceous aerosols in the Canadian Centre for Climate Modeling and Analysis Atmospheric General Circulation Model with impacts on global radiation and energy fluxes, J. Geophys. Res., 112, D10207, doi:10.1029/2006JD007319, 2007.

Chýlek, J. and Wong, J. G. D.: Effect of absorbing aerosols on global radiation budget, J. Geophys. Res. Lett., 22, 929-931, 1995.

Haywood, J. M., Ramaswamy, V., and Donner, L. J.: A limitedarea-model case study of the effects of sub-grid scale variations in relative humidity and cloud upon the direct radiative forcing of sulfate aerosol, Geophys. Res. Lett., 24, 143-146, 1997.

Haywood, J. M. and Shine, K. P.: Mult-spectral calculations of the direct radiative forcing of tropospheric sulphate and soot aerosols using a column model, Q. J. R. Meteorol. Soc., 123, 1907-1930, 1997.

Dobbie, J. S., Li, J., and Chýlek, P.: Two and Four Stream Optical Properties for Water Clouds and Solar Wavelengths, J. Geophys. Res., 104, 2067-2079, 1999.

Dobbie, J. S., Li, J. Harvey, R., and Chýlek, P.: Sea-salt optical properties and GCM forcing at solar wavelengths, Atmos. Res., 65 (special issue for aerosol), 211-233, 2003.

Fitzgerald, J. W.: Approximation formulas for the equilibrium size of an aerosol particle as a function of its dry size and composition and the ambient relative humidity, J. Appl. Meteor., 14, 10441049, 1975

Hale, G. M. and Querry, M. R.: Optical constants of water in the $200 \mathrm{~nm}$ to $200 \mathrm{um}$ wavelength region, Appl. Opt., 12, 555-563, 1973.

Holben B. N., Eck, T. F., Slutsker, I., Tanre, D., Buis, J. P., Setzer, A., Vermote, E., Reagan, J. A., Kaufman, Y., Nakajima, T., Lavenu, F., Jankowiak, I., and Smirnov, A.: AERONET - A federated instrument network and data archive for aerosol characterization, Rem. Sens. Environ., 66, 1-16, 1998.

Koepke, P., Hess, M., Schult, I., and Shettle, E. P.: Global Aerosol Data Set. Report No. 243 of the Max-Planck-Institut für Meteorologie, Hamburg, ISSN 0937-1060, 44 pp., 1997.

Lewis, E. R. and Schwartz, S. E.: Sea salt aerosol production: Mechanisms, methods, measurements and models - a critical review, 413 pp., Geophysical Monograph, 152, 2004.
Lewis, E. R. and Schwartz, S. E.: Comment on size distribution of sea-salt emissions as a function of relative humidity, Atmos. Env., 40, 591-592, 2006.

Lewis, E. R.: An examination of Köhler theory resulting in an accurate expression for the equilibrium radius ratio of a hygroscopic aerosol particle valid up to and including relative humidity $100 \%$, J. Geophys. Res., 113, D03205, doi:10.1029/2007JD008590, 2008.

Li, J., Wong, J. G. D., Dobbie, J. S., and Chýlek, P.: Parameterization of the optical properties and growth of sulfate aerosols. J. Atmos. Sci., 58, 193-209, 2001.

Li, J.: Accounting for unresolved clouds in a 1-D infrared radiative transfer model. Part I: Solution for radiative transfer, cloud scattering, and overlap, J. Atmos. Sci., 59, 3302-3320, 2002.

Li, J. and Min, Q.: Parameterization of the optical properties of sulfate aerosols in the in the infrared, J. Atmos. Sci., 59, 31303140, 2002.

Li, J. and Barker, H. W.: A radiation algorithm with correlated kdistribution. Part I: local thermal equilibrium, J. Atmos. Sci., 62, 286-309, 2005.

Li, J., Scinocca, J., Lazare, M., McFarlane, N., von Salzen, K., and Solheim, L.: Ocean surface albedo and its impact on radiation balance in climate models, J. Climate, 19, 6314-6333, 2006.

Ma, X. Y. and von Salzen, K.: Dynamics of the sulphate aerosol size distribution on a global scale, J. Geophys. Res., 111, D08206, doi:10.1029/2005JD006620, 2006.

Ma, X. Y., von Salzen, K., and Li, J.: Modelling sea-salt aerosol and its direct and indirect effects, Atmos. Chem. Phys., 8, 13111327, 2008, http://www.atmos-chem-phys.net/8/1311/2008/.

McClatchey, R. A., Fenn, R. W., Selby, J. E. A., Volz, F. E., and Garing, J. S.: Optical properties of the atmosphere, 3rd ed., AFCRL72-0497, 108 pp., [NTIS N7318412], 1972.

O’Dowd, C. D., Lowe, J. A., Smith, M. H., and Kaye, A. D.: The relative importance of non-sea-salt sulphate and sea-salt aerosol to the marine cloud condensation nuclei population: An improved multi-component aerosol-cloud droplet parameterization, Quart. J. R. Meteorol. Soc., 125, 1295-1313, 1999.

Penner, J. E., Andrea, M., Annegarn, H., Barrie, L., Feichter, J., Hegg, D., Jayaraman, A., Leaitch, R., Murphy, D., Nganga, J. and Pitari, G.: Aerosols, their direct and indirect effects: The Scientific Basis. Contribution of Working Group I to the Third Assessment Report of the Intergovernmental Panel on Climate Change, in: IPCC Third Assessment Report, edited by: Houghton, J. T., Ding, Y., Griggs, D. J., Noguer, M., van der Linden, P. J., Dai, X., Maskell, K., and Johnson, C. A., Cambridge Univ. Press, New York, NY, USA, Clim. Change, 289-348, 2001.

Schulz, M., Textor, C., Kinne, S., Balkanski, Y., Bauer, S. Berntsen, T., Berglen, T., Boucher, O., Dentener, F., Grini, A., Guibert, S., Iversen, T., Koch, D., Kirkevag, A., Liu, X., Montanaro, V., Myhre, G., Penner, J., Pitari, G., Reddy, S., Seland, O., Stier, P., and Takemura, T.: Radiative forcing by aerosols as derived from the AeroCom present-day and pre-industrial simulations, Atmos. Chem. Phys., 6, 5225-5246, 2006,

http://www.atmos-chem-phys.net/6/5225/2006/.

Shettle, E. P. and Fenn, R. W: Models for the Aerosols of the Lower Atmosphere and the Effects of Humidity Variations on Their Optical Properties, AFGL-TR-79-0214, ADA085951, 20 September 1979 . 
von Salzen, K.: Piecewise log-normal approximation of size distributions for aerosol modelling, Atmos. Chem. Phys., 6, 13511372, 2006, http://www.atmos-chem-phys.net/6/1351/2006/.

Tang, I. N., Tridico, A. C., and Fung, K. H.: Thermodynamic and optical properties of sea-salt aerosols, J. Geophys. Res., 102, 23 269-23 275, 1997.

Volz, F. E.: Infrared refractive index of atmospheric aerosol substance, Appl. Opt., 11, 755-759, 1972.
Wang, J. and Martin, S. T. : Satellite characterization of urban aerosols: importance of including hygroscopicity and mixing state in the retrieval algorithms, J. Geophys. Res., 112, D17203, doi:10.1029/2006JD008078, 2006.

Winter, B. and Chýlek, P.: Contribution of sea-salt aerosol to the planetary clear-sky albedo Tellus Series B, 49, 72-79, 1997. 